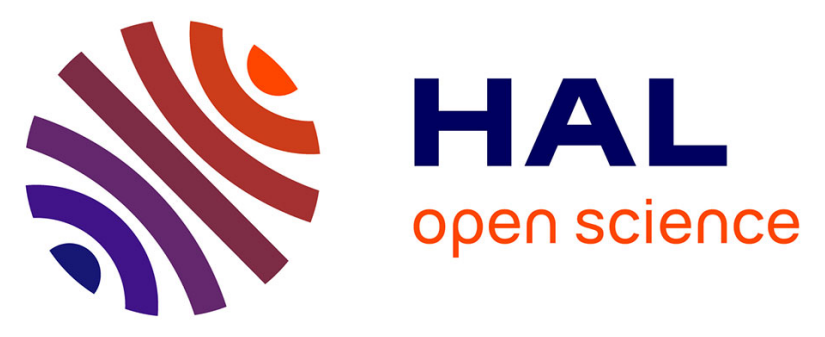

\title{
Wood fiber orientation assessment based on punctual laser beam excitation: A preliminary study
}

Mohamed Belkacemi, Joan Massich, Guillaume Lemaître, Christophe Stolz, Vincent Daval, Guillaume Pot, Olivier Aubreton, Robert Collet, Fabrice Meriaudeau

\section{To cite this version:}

Mohamed Belkacemi, Joan Massich, Guillaume Lemaître, Christophe Stolz, Vincent Daval, et al.. Wood fiber orientation assessment based on punctual laser beam excitation: A preliminary study. 13th Quantitative Infrared Thermography Conference (QIRT), Jul 2016, Gdansk, Poland. hal-01320156

\section{HAL Id: hal-01320156 https://u-bourgogne.hal.science/hal-01320156}

Submitted on 23 May 2016

HAL is a multi-disciplinary open access archive for the deposit and dissemination of scientific research documents, whether they are published or not. The documents may come from teaching and research institutions in France or abroad, or from public or private research centers.
L'archive ouverte pluridisciplinaire HAL, est destinée au dépôt et à la diffusion de documents scientifiques de niveau recherche, publiés ou non, émanant des établissements d'enseignement et de recherche français ou étrangers, des laboratoires publics ou privés. 


\title{
Wood fiber orientation assessment based on punctual laser beam excitation: A preliminary study
}

\author{
by M. Belkacemi, J. Massich*, G. Lemaitre*, C.Stolz*, V. Daval ${ }^{* *}$, G. Pot $^{* *}$, O.Aubreton*, R. Collet** \\ and F. Meriaudeau*** \\ *Université Bourgogne Franche-Comté, LE2I UMR6306, CNRS, Arts et Métiers, 12 rue de la Fonderie, Le \\ Creusot 71200, France \\ **LaBoMaP, Ecole Nationale Supérieure d'Arts et Métiers, Rue porte de Paris, Cluny, 71250, France \\ *** Centre for Intelligent Signal and Imaging Research (CISIR), Electrical \& Electronic Engineering Department, \\ Universiti Teknologi Petronas, 32610 Seri Iskandar, Perak, Malaysia
}

\begin{abstract}
The EU imposes standards for the use of wood in structural applications. Local singularities such as knots affect the wood mechanical properties. They can be revealed by looking at the wood fiber orientation. For this reason, many methods were proposed to estimate the orientation of wood fiber using optical means, X-rays, or scattering measurement techniques. In this paper, an approach to assess the wood fiber orientation based on thermal ellipsometry is developed. The wood part is punctually heated with a Nd-YAG Laser and the thermal response is acquired by an infrared camera. The thermal response is elliptical due to the propagation of the heat through and along the wood fibers. An experiment is presented to show the capacity of such techniques to assess fiber orientation on wood specimen. In addition, an appropriate algorithm is given to extract the orientation of the ellipse.
\end{abstract}

\section{Introduction}

Wood is considered as an anisotropic material composed of fibers aligned in the longitudinal direction of the tree. An accurate estimation of the wood fiber orientation is an interesting information to model the mechanical behaviour of timber [1]. In the state-of-the-art on Non-Destructive Testing (NDT), a method to assess the orientation of the fiber known as the capacitance technique has been proposed [2]. However, this technique is difficult to implement and sensitive to moisture [3]. Nyström et al. infer the fiber orientation using the tracheid effect technique [4]. The method consists in projecting a laser dot on the wood surface; the light propagates in the wood fiber and the observed pattern is elliptical. Thus, the orientation of the wood fiber is derived from the ellipse orientation.

Active Thermography is one of the methods widely used in NDT; the technique consists in applying an external heat on the surface object to be inspected and the thermal response of the material is analysed. This technique allows detecting non-through defect on metallic object [5], fiber orientation on composite material [6], crack detection [7], and has many other applications [8]. Several approaches based on heat propagation have been proposed to detect material anisotropy, De Senarmont et al. have applied a punctual thermal excitation on crystal plates covered with a thin layer of wax [9], the monitored isotherm is elliptical and its aspect ratio is equal to the square root of the principal conductivities in the surface plane. This technique later on, was called "thermal ellipsometry" by Krapez et al. [10]. Other studies have shown that the conductivity is larger in the longitudinal direction of wood fiber than in the orthogonal directions [11]. In fact, Kollmann et al. have shown that wood thermal conductivity depends on fiber direction [12]

In this study, the thermal ellipsometry phenomenon is used to asses wood fiber orientation. The inspected wood part is heated by a laser beam and an IR camera records the heat which propagates through the fiber. Due to the heat propagation, the pattern is elliptical and the orientation of the fiber is deduced from the ellipse orientation.

\section{Fiber orientation assessment}

\subsection{Experimental setup}

The fiber orientation is assessed through the "Scanning From Heating" (SFH) system initially used for threedimensional digitization of transparent and metallic object [13,14, 15,16]. Recently, the system has been extended to detect sub-surface defect on metallic object as well as fiber orientation assessment in carbon composite material [17]. The system is composed of:

1) A FLIR $645 \mathrm{IR}$ camera with a sensitivity range from 7.5 to $14 \mu \mathrm{m}$, the IR camera acquires a $640 \times 480$ pixels images. 
2) A Nd: YAG laser of $1.06 \mu \mathrm{m}$ wavelength coupled with a galvanometer scan-head of two mirrors to control the position of the laser beam, the angle between the IR Camera and the galvanometer scan head is approximately equal to $45^{\circ}$. The collimated laser beam passes through the two mirrors of the scan head and is projected on the wood surface.

3) A rotary stage (Ref: ZABER T-RS60A) on which the wood specimen is fixed. The device is placed at a distance of $50 \mathrm{~cm}$ from the output focal. Indeed, the optical system is equipped by a lens focal length of 500 $\mathrm{mm}$ which allows obtaining a beam waist of $0.44 \mathrm{~mm}$ at the previously mentioned distances (Fig. 1 (b)).

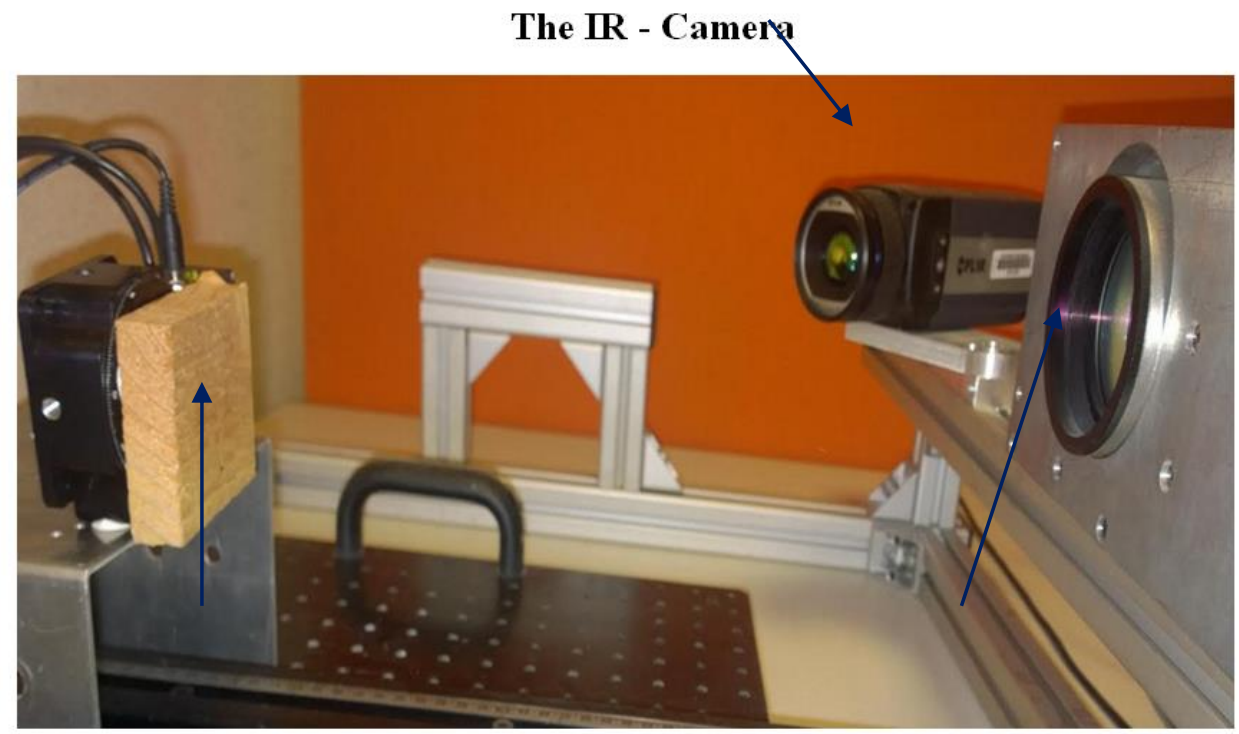

The Rotary stage

The Galvanometer scan-head

(a)

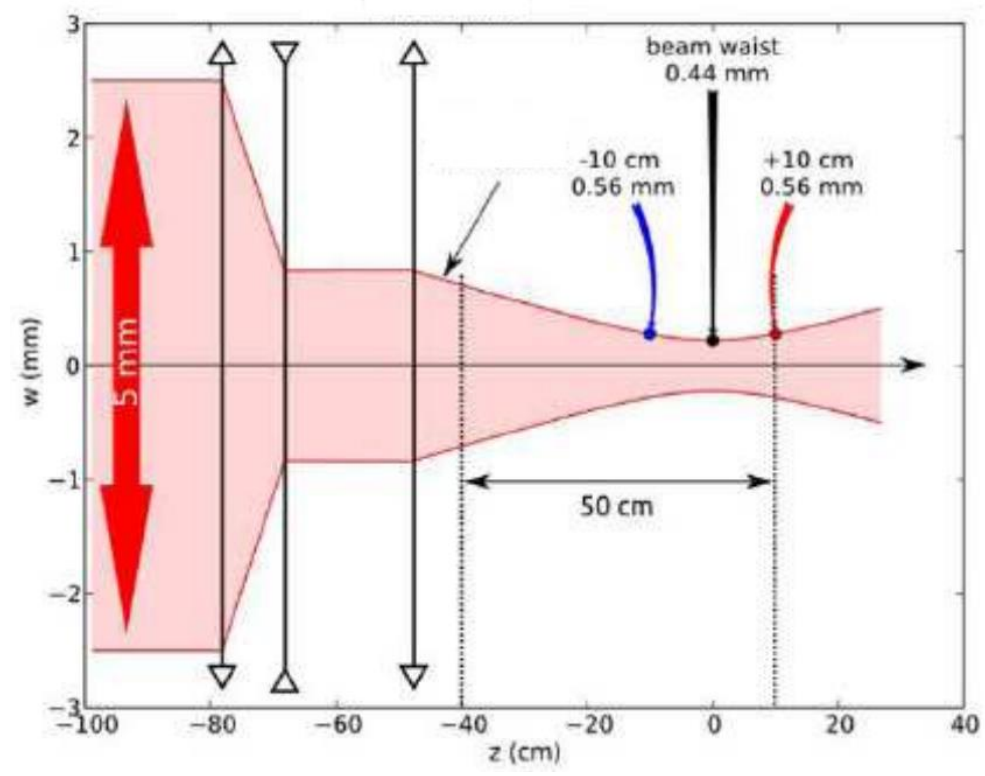

(b)

Fig. 1. (a) Experimental Setup, (b) beam focusing optics. 


\subsection{Proposed method}

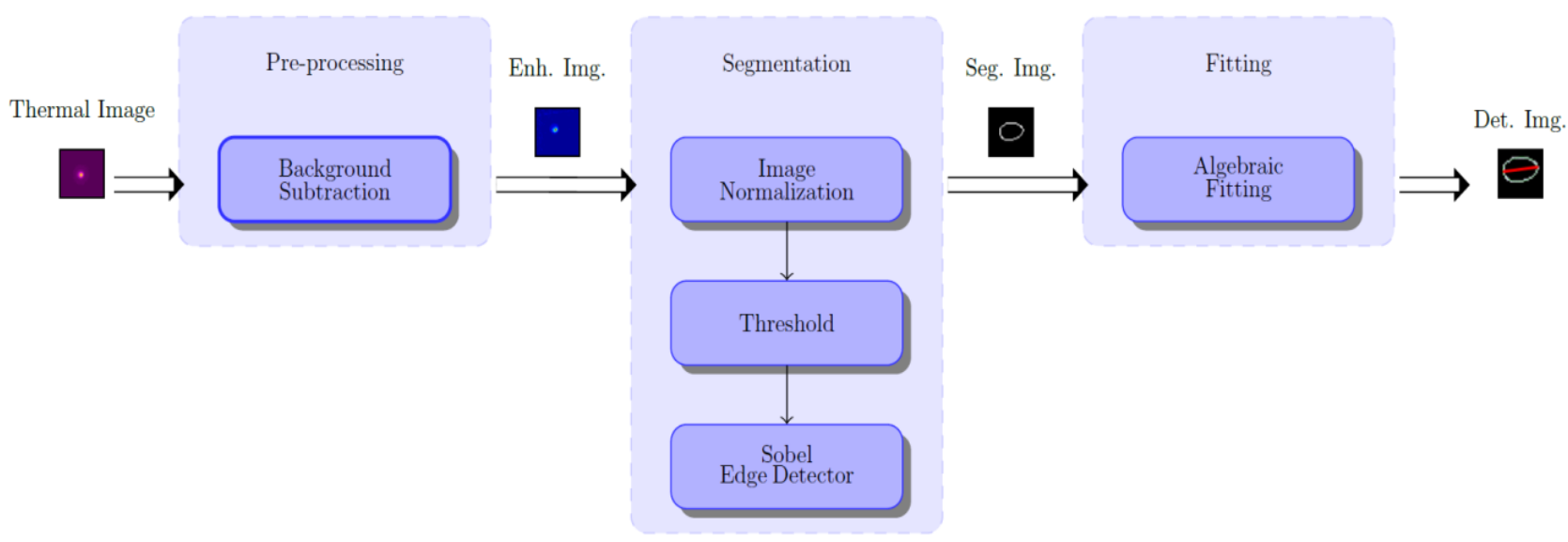

Fig. 2. Image processing framework

The fiber orientation is estimated based on the thermal ellipsometry approach. Indeed, the thermal response of the wood stimulated by a laser beam is elliptical due to the propagation of the heat through the fiber. Thermal images are acquired with an IR camera and are processed with the following steps:

(i) Preprocessing: Each infrared image is enhanced by subtracting the background (infrared image acquired before laser heating). Additionally, to reduce the noise, a median filtering is applied.

(ii) Segmentation: Firstly, the enhanced image is normalized according to the following formula:

$$
I_{\text {Nor }}=\frac{\left(I_{E n h}-\operatorname{Min}\left(I_{E n h}\right)\right)}{\operatorname{Max}\left(I_{E n h}\right)}
$$

Where $\operatorname{Min}($.$) and \operatorname{Max}($.$) represent the minimum and the maximum value of the enhanced$ image $\left(I_{E n h}\right)$ respectively. Once the $I_{\text {Nor }}$ computed, the next step is to binarize the normalized IR-image by applying an appropriate threshold determined experimentally, in our experiment the threshold is set to 0.5 . An intensity of 1 is assigned to all pixels intensities higher than the threshold; the remaining pixels are set to 0 . The final step consists in determining the edge of the binarized ellipse. To this end, a Sobel edge detector is used [18].

(iii) Ellipse fitting: Once edges are detected, an ellipse is fitted through a least square minimization [19].

\section{Experimental results}

The setup used for the experiment is the same as depicted in Fig. 1. The experiment is conducted on a softwood specimen. The specimen is punctually heated with a laser beam. The heat signal is a step signal of $1 \mathrm{~s}$ period and the power of the laser beam is set to $1 \mathrm{~W}$. The thermal response is recorded with the IR-camera. The fiber orientation is assessed with the algorithm described in Sec. 2.2. Figure 3 shows the resulting outputs at the different stages of the algorithm (i.e., preprocessing, segmentation, ellipse fitting). The results show that the fitted ellipse in green follow the thermal response and the red axis represents the ellipse orientation, as depicted in Fig.3 (e).

To determine if the ellipse orientation follows the wood fiber, we have set up the following experiment. The first step consists in positioning the planar wood specimen to be inspected on the rotary stage. Then, the device is placed in front of the laser scan head. In order to heat the same area for each laser stimulation, the orientation center of the rotary stage and the central beam must be on the same axis. This configuration is obtained when the wood thermal response produced by the central laser beam is located at the same area for each rotational position of the wood specimen.

Finally, rotations of $10^{\circ}$ are carried out after each laser stimulations (this step is replicated 9 times, thus a $90^{\circ}$ rotation), and five stimulation are done for each rotational position. Two IR-images are acquired after and before each stimulation.

Figure 4 shows ten fitted ellipses for ten rotational positions. We can easily observe the evolution of the ellipse orientation, and the orientation follows the rotation of the wood specimen. We can thus say that the ellipse orientation refer to the wood fiber orientation. 


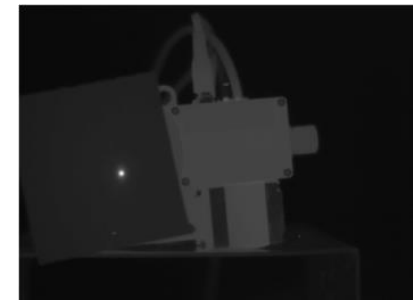

(a)

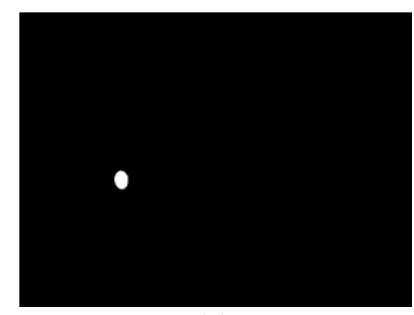

(c)

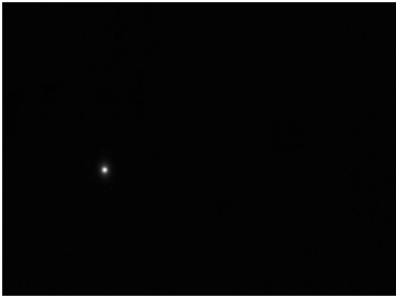

(b)

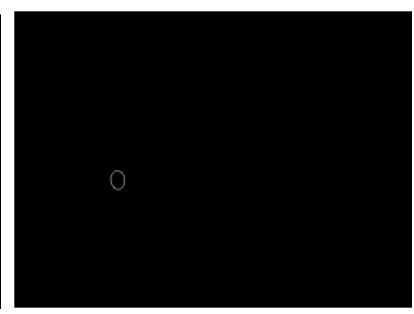

(d)

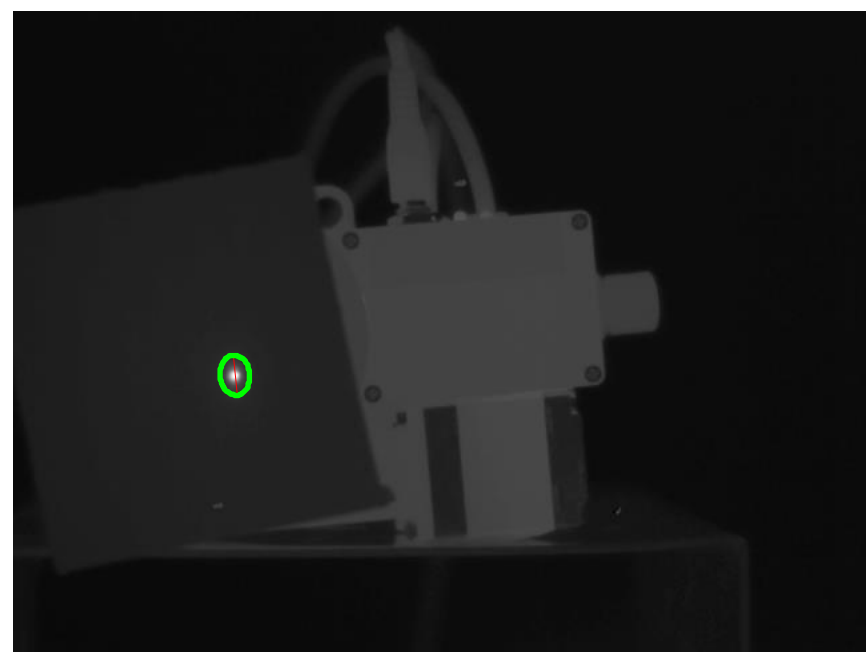

(e)

Fig. 3. Ellipse orientation assessment. (a) acquired IR-image, (b) enhanced image, (c) normalized image, (d) Segmented image, (e) ellipse fitting.

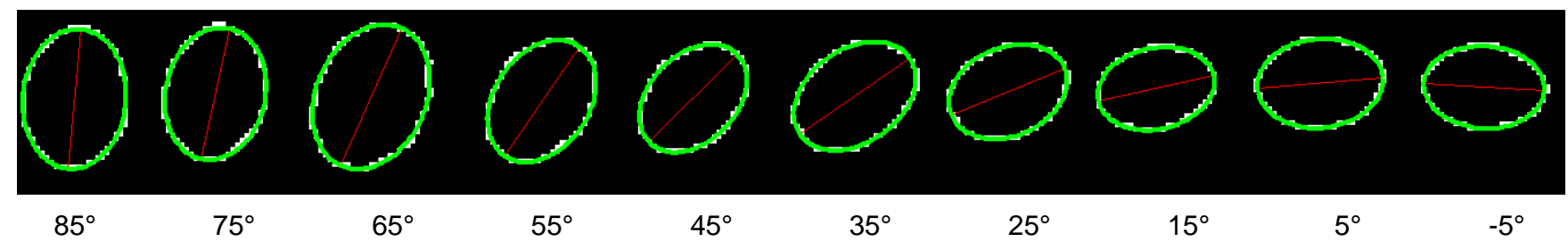

Fig. 4. Ellipse orientation assessment.

In an attempt to estimate the error of our method, the mean and standard deviation are computed using the five measurements of each position presented in Table 1. The results are illustrated in Fig. 5 through a probability density function. The results shows that the fiber orientation evaluation follows the absolute rotation of the rotary stage. Indeed, the probabilistic histograms shows that the mean relative orientation is $10.01^{\circ}$ which is close to the absolute rotation step. However, the relative fiber orientation suffers from a large standard deviation $\left(2.02^{\circ}\right)$. This is due to two reasons: (i) the rotation step is done manually, causing an uncertainty on the rotation step value and (ii) the center of the rotary stage and the central laser beam are not always aligned, implying some measurements errors. 


\begin{tabular}{|l|l|l|l|l|l|l|l|l|l|l|}
\hline & $85^{\circ}$ & $75^{\circ}$ & $65^{\circ}$ & $55^{\circ}$ & $45^{\circ}$ & $35^{\circ}$ & $25^{\circ}$ & $15^{\circ}$ & $5^{\circ}$ & $-5^{\circ}$ \\
\hline 1st measure & 84.65 & 78.40 & 65.46 & 55.92 & 45.60 & 34.96 & 22.66 & 11.49 & 5.25 & -3.57 \\
\hline 2nd measure & 85.73 & 76.42 & 66.52 & 57.31 & 44.84 & 34.43 & 24.14 & 13.49 & 5.77 & -3.87 \\
\hline 3rd measure & 87.36 & 77.60 & 66.91 & 57.96 & 44.83 & 31.02 & 24.00 & 12.77 & 5.09 & -5.48 \\
\hline 4th measure & 84.65 & 78.40 & 65.46 & 55.92 & 45.60 & 34.96 & 22.66 & 16.05 & 5.43 & -5.62 \\
\hline 5th measure & 88.03 & 75.36 & 69.37 & 57.96 & 43.30 & 32.74 & 24.95 & 13.93 & 4.81 & -1.55 \\
\hline Average & 86.08 & 77.23 & 66.75 & 56.96 & 44.83 & 33.62 & 23.68 & 13.54 & 5.27 & -4.02 \\
\hline
\end{tabular}

Tab. 1. Measurements of fiber orientation.

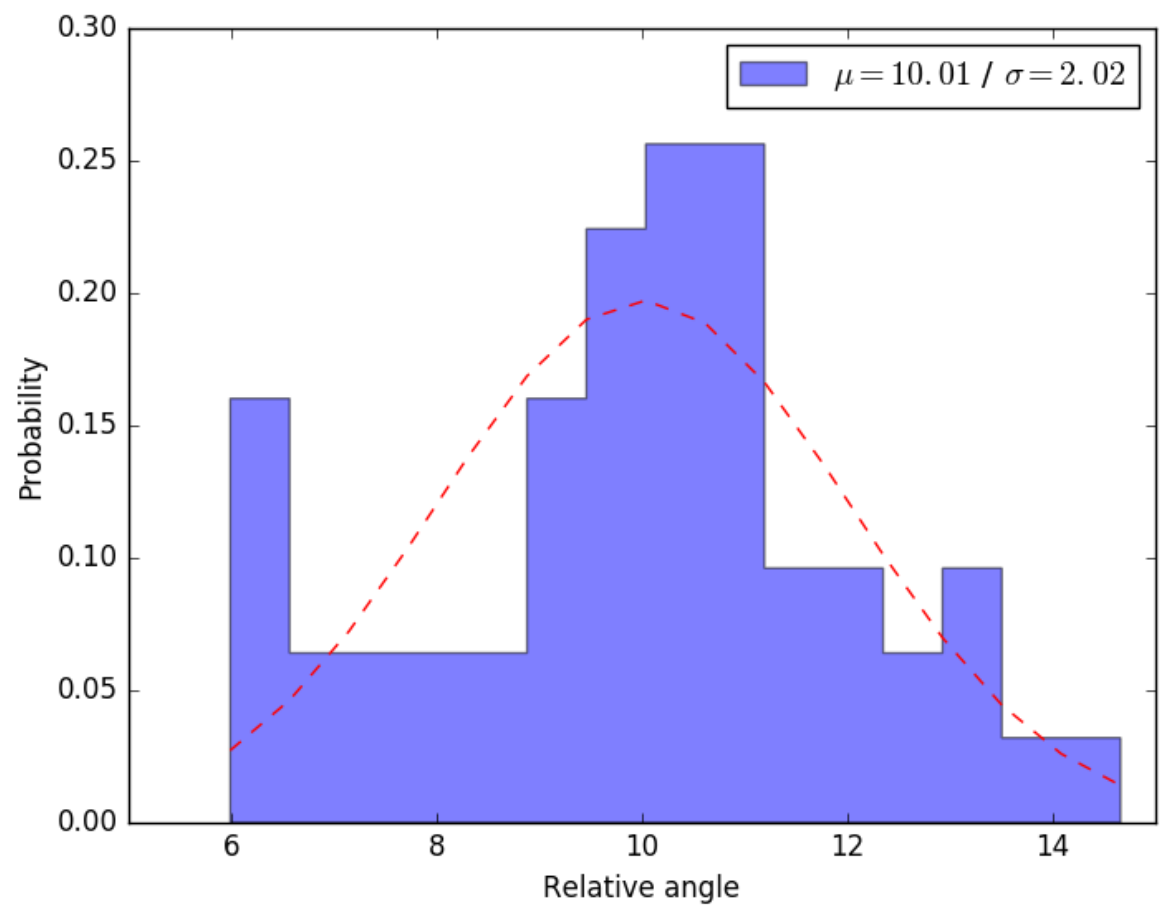

Fig. 5. Probability density function.

\section{Conclusion}

The use of infrared ellipsometry for wood fiber orientation assessment is presented in this paper. The experiment results show a good correlation between the wood fiber orientation and ellipse orientation. The next step is to compare these results with techniques in the state-of-the-art to verify the accuracy. Furthermore, the technique will be applied on different wood species to verify its robustness. In another hand, the SFH approach offer us the possibility to get the 3D shape of the inspected wood specimen. Indeed, in the case of a non planar specimen the fiber orientation assessment is disturbed by the shape of the object. Therefore, the $3 \mathrm{D}$ information is essential to perform an accurate estimation of the fiber orientation.

\section{Acknowledgments}

This work is supported by the Regional Council of Burgundy and the French National Research Agency through the ANR CLAMEB project (ANR-11-RMNP-0015). We are extremely grateful to members of laboratory LE2I for day to day help and collaboration. 


\section{REFERENCES}

[1] Viguier, J., Jehl, A., Collet, R., Bleron, L. and Meriaudeau, F. , "Improving strength grading of timber by grain angle measurement and mechanical modeling," Wood Material Science \& Engineering 10(1), 145-156 (2015).

[2] Steele, P. H., Neal, S. C., McDonald, K. A. and Cramer, S. M. , "The slope-of-grain indicator for defect detection in unplaned hardwood lumber," For.Prod.J. 41(1), 15-20 (1991).

[3] de Senarmont, H., [Mémoire Sur La Conductivité Des Substances Cristallisées Pour La Chaleur: Second Mémoire], Imprr. de Bachelier (1848).

[4] Nyström, J. , "Automatic measurement of fiber orientation in softwoods by using the tracheid effect," Comput.Electron.Agric. 41(1), 91-99 (2003).

[5] Wu, D. and Busse, G. , "Lock-in thermography for nondestructive evaluation of materials," Revue générale de thermique 37(8), 693-703 (1998).

[6] Fernandes, H. and Maldague, X. , "Fiber orientation assessment in complex shaped parts reinforced with carbon fiber using infrared thermography," Quantitative InfraRed Thermography Journal 12(1), 64-79 (2015).

[7] Li, T., Almond, D. P. and Rees, D. A. S. , "Crack imaging by scanning pulsed laser spot thermography," NDT E Int. 44(2), 216-225 (2011).

[8] Legrand, A., Meriaudeau, F. and Gorria, P. , "Active infrared non-destructive testing for glue occlusion detection within plastic lids," NDT E Int. 35(3), 177-187 (2002).

[9] de Senarmont, H., [Mémoire Sur La Conductivité Des Substances Cristallisées Pour La Chaleur: Second Mémoire], Imprr. de Bachelier (1848).

[10] Krapez, J., Gardette, G. and Balageas, D. , "Thermal ellipsometry in steady-state and by lock-in thermography. Application to anisotropic materials characterization," OFFICE NATIONAL D ETUDES ET DE RECHERCHES AEROSPATIALES ONERA-PUBLICATIONS-TP (1996).

[11] MAKu, T. , "Studies on the Heat Conductin in Wood: The present study is a discussion on the results of investigations made hitherto by author on heat conduction in wood." 木材研究: 京都大學木材研究所報告 13, 180 (1954).

[12] Kollmann, F. F. and Côté Jr, W. A. , "Principles of wood science and technology. vol. I. Solid Wood," (1968).

[13] Bajard, A., Aubreton, O., Fofi, D., Morel, O., Truchetet, F. and Meriaudeau, F., "Non conventional Imaging Systems for 3D Digitization of transparent and/or specular manufactured objects," QCAV2013, 11th Interntional Conference on Quality Control by Artificial Vision, 190-197 (2013).

[14] Aubreton, O., Bajard, A., Verney, B. and Truchetet, F. , "Infrared system for 3D scanning of metallic surfaces," Mach Vision Appl 24(7), 1513-1524 (2013).

[15] Eren, G., Aubreton, O., Meriaudeau, F., Secades, L. S., Fofi, D., Naskali, A. T., Truchetet, F. and Ercil, A. , "Scanning from heating: 3D shape estimation of transparent objects from local surface heating," Optics Express 17(14), 11457-11468 (2009).

[16] Mériaudeau, F., Secades, L., Eren, G., Erçil, A., Truchetet, F., Aubreton, O. and Fofi, D. , "3-D scanning of nonopaque objects by means of imaging emitted structured infrared patterns," Instrumentation and Measurement, IEEE Transactions on 59(11), 2898-2906 (2010).

[17] Belkacemi, M., Stolz, C., Mathieu, A., Lemaitre, G., Massich, J. and Aubreton, O. , "Nondestructive testing based on scanning-from-heating approach: application to nonthrough defect detection and fiber orientation assessment," Journal of Electronic Imaging 24(6), 061112-061112 (2015).

[18] Matthews, J. An introduction to edge detection: The sobel edge detector (2002).

[19] Fitzgibbon, A., Pilu, M. and Fisher, R. B. , "Direct least square fitting of ellipses," Pattern Analysis and Machine Intelligence, IEEE Transactions on 21(5), 476-480 (1999). 